\title{
A MAN WITH ISCHEMIC HEART DISEASE AFTER CONSUMING ALCOHOL FOUND COLLAPSED WHILE EATING: A CAFÉ CORONARY AND INTOXICATION. WHICH CAUSE PRECEDED THE OTHERS?
}

\author{
Gangahawatte S. ${ }^{1}$, Edirisinghe P.A.S. ${ }^{2} \&$ Kitulwatte I.D.G. ${ }^{2}$ \\ ${ }^{1}$ Office of the JMO, North Colombo Teaching Hospital Ragama, Sri Lanka \\ ${ }^{2}$ Department of Forensic Medicine, Faculty of Medicine, University of Kelaniya, Sri Lanka
}

\begin{abstract}
Introduction

Complete and abrupt upper airway obstruction by a bolus of food, with sudden onset of symptoms simulating acute myocardial infarction was described as 'Café coronary' in early 60s. Victims are speechless and breathless; thus, without assistance (e.g.Heimlich manoeuvre) they will die.
\end{abstract}

A typical 'café coronary' was an obese middle aged man dying, while eating having a chest pain, with eye witness accounts of 'choking on a piece of meat' which was hurriedly eaten. Though various theories were postulated at that time regarding the mechanism, later studies showed that multiple factors could be associated.

We report a death of an alcoholic with a history of ischemic heart disease found with a bolus of food lodged at the pharynx and larynx.

\section{Case Report}

51 year-old male after having $1 \frac{1 / 2}{2}$ bottles of illicit liquor, quarreled with the wife and left home, was found dead two (2) hours later in a partly built house. The examination of the scene revealed half a bottle of alcohol, a partly consumed loaf of bread, a beef curry and a roasted chicken thigh beside.
Autopsy revealed obstruction of the mid larynx with a piece of bread, mild laryngeal oedema, myocardial fibrosis, $80 \%$ narrowing of the anterior descending artery and a liquor smell from stomach. The toxicological screening revealed $200 \mathrm{mg} /$ dlethyl alcohol in the blood, while histology revealed fibrosis of the myocardium.

\section{Conclusion}

Although obstruction of the airway with a food bolus was the apparent cause of death at autopsy, the high blood alcohol level with myocardial fibrosis pauses questions regarding the mechanism of death i.e. which caused which? Therefore, a forensic pathologist should not be hurried to arrive at conclusions during the autopsy without further investigations.

Key words: alcoholic, ischemic heart disease, bolus of food, cafe coronary

Corresponding author: sangikenu@gmail.com 


\section{INTRODUCTION}

Middle aged person's collapsing, while eating erroneously, was thought to be due to ischemic heart disease, was termed as 'café coronary': Sudden deaths in restaurants, by Haugen in 1963, was found to be due to complete and abrupt upper airway obstruction by a bolus of food, especially at the glottis. ${ }^{1}$ Although the mechanism of death is asphyxial in nature i.e. choking, many reasons have been postulated as underlying or contributory factors, such as elderly or very young; edentulous status, gulping of food, neurological impairments ranging from cerebro-vascular disease to parkinsonism, sedatives, anti-psychotics and alcohol. ${ }^{2,3,4,5}$ Choking or foreign body impact in the upper respiratory tract is an emergency where the victims are speechless and breathless,; thus without assistance (e.g.Heimlich manoeuvre) they will die. ${ }^{6}$ Though investigating of a 'typical café coronary' or a choking death due to impact of a bolus of food in the upper-air way looks easy, when multiple pathologies are existing, it has often become difficult and even impossible to postulate the exact mechanism of death. We report a sudden death of an alcoholic with history of ischemic heart disease with a bolus of food lodged at the pharynx and larynx at the autopsy.

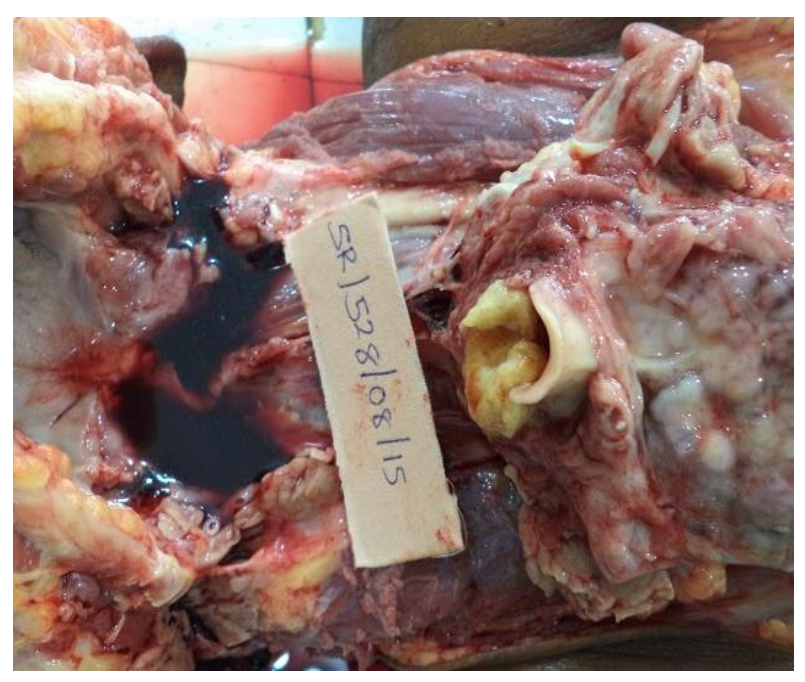

Photograph 1: the obstruction at larynx

\section{CASE REPORT}

51 year-old chronic alcoholic, after consuming $1 \frac{1 / 2}{2}$ bottles of illicit liquor, has come home in the evening and asked about dinner. When his wife told its bread and pol sambol, he had assaulted her and left home. Two (2) hours later, his son found him collapsed in a partly built house next to their home. When he was brought to the hospital, he was pronounced dead. The examination of the scene revealed half a $(1 / 2)$ bottle of alcohol, a partly consumed loaf of bread, a beef curry and a roasted chicken thigh where the deceased was found. According to the family, although he was suffering from ischemic heart disease and hypertension, he has not been taking medication regularly.

The autopsy revealed almost complete obstruction of the mid larynx with a piece of bread (Photograph 1 and 2), mild laryngeal oedema, myocardial fibrosis, $80 \%$ narrowing of the anterior descending artery and a liquor smell from stomach. The toxicological screening revealed $200 \mathrm{mg} / \mathrm{dl}$ ethyl alcohol in the blood, while histology revealed fibrosis of the myocardium.

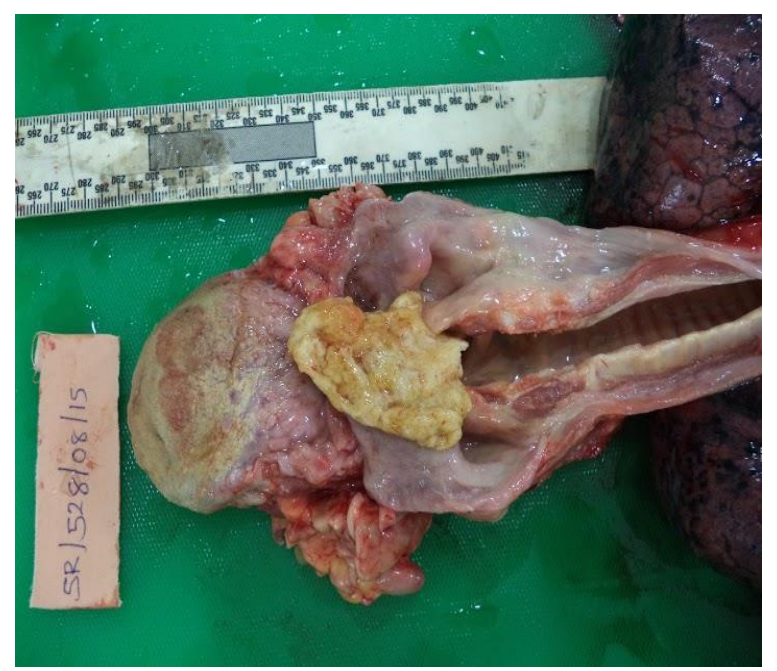

Photograph 2: the food bolus at mid larynx 


\section{DISCUSSION}

Medico-legal investigation of a sudden death involves not only finding the cause of death, but also the possible mechanism of death, as well as an opinion on historical corroborations leading to circumstance of death. The case on discussion had three main findings; namely, bolus of food obstructing the air way, high blood alcohol level, coronary atherosclerosis and fibrosis of the heart.

A food bolus obstructing the airway leading to reduction of oxygenation of the blood will cause death within a few minutes. In fact, it is well known that the brain cells cannot survive without oxygen for more than 4 minutes. Thus, in choking, death is very quick because the airway is obstructed and the oxygenation cannot take place in the lungs. Although hypoxia is the most likely mechanism in choking, most of the times features of anoxia or hypoxia such as oedema, cyanosis, petechiae, are usually absent, since there is no effects on venous drainage. Since the death is quite rapid, an alternative mechanism has been suggested in forensic literature i.e. neurogenic cardiac arrest following vagal stimulation. ${ }^{7,8}$ Although both mechanisms are possible in any death, whether death is due to only one mechanism is impossible to comment. As literature on café coronary mechanism of death has been debated, it is most likely that both mechanisms operate at a given time. ${ }^{9,10,11}$

Alcohol is a cerebral depressant and it is well known that blood alcohol affects all neurological functions including the cough and gag reflexes. Blood alcohol above $300 \mathrm{ml}$ is known to cause alcohol poisoning and death due to effects on the vital centers of the brain. ${ }^{12}$ The deceased had a blood alcohol level of $200 \mathrm{mg} / \mathrm{dl}$; although it is not at a level producing coma and death, it is a very significant high level to have a reduction in the reflexes. Thus, it can be concluded that alcohol level of this person had an effect on gag and couch reflex, which is needed to save his life, thus leading to neurogenic cardiac arrest. Further, alcohol is known to cause ventricular arrhythmias and sudden death. ${ }^{13}$ Hence, the contribution of alcohol to either situations is a high possibility rather than a probability.

The presence of ischemic heart disease is a factor which we have to consider if we are to find which preceded which. Fibrosis of the heart is a well-known factor causing ventricular fibrillation and as well as other forms of arrythmia especially when combined with alcohol and emotion. ${ }^{13}$ Since ventricular tachycardia is a physiological phenomenon, postmortem signs/ findings are often absent. Thus, analyzing autopsy findings and postulating possible mechanisms is crucial to a forensic pathologist especially in a situation of this nature where death has not been witnessed.

The type of food being consumed is a significant factor in these types of deaths. Although 'Café coronary' was first reported while eating meat with alcohol, a large series of café coronary deaths caused by other soft or semisolid food have also been found being involved, especially when they do not have molar teeth for mastication. ${ }^{14,15}$ Although studies on café coronary deaths are hardly found from South Asian region where food consist of more fiber/vegetable material, two case reports of café coronary death due to banana are reported from Sri Lanka and India. ${ }^{16,17}$

\section{CONCLUSION}

Obstruction of the airway with a food bolus when found in association with high blood alcohol level and myocardial fibrosis, a forensic pathologist has to pause regarding the mechanism of death i.e. which caused which before giving an opinion. In this case, although the main cause was choking, the contribution of alcohol and the ischemic 
heart disease were significant because they too can contribute to death as well as mechanisms of death. Thus, a forensic pathologist should not be hurried to come to conclusions at autopsy without further investigations.

\section{REFERENCES}

1. Haugen RK. The cafe' coronary. Sudden deaths in restaurants. JAMA 1963;186:1423.

2. Mittleman RE, Wetli CV. The fatal cafe coronary. Foreign-body airway obstruction. JAMA 1982;247:1285-8.

3. Mittleman RE. Fatal choking in infants and children. Am J Forensic Med Pathol. 1984 Sep;5(3):201-10.

4. Ruschena D, Mullen PE, Palmer S, Burgess $\mathrm{P}$, Cordner SM, Drummer, $\mathrm{OH}$, et al. Choking deaths: the role of antipsychotic medication. Br J Psychiat 2003;183:446-50.

5. Kumar MV, Venkatesh VT, Jagannatha SR. Fast eating syndrome: a case report. Med Sci Law. 2008 Jan;48(1):78-81.

6. Kitay G, Shafer N. Cafe coronary: recognition, treatment and prevention. Nurse Pract. 1989 Jun;14(6):35-8,43,46.

7. Suffocation and asphyxia in Knight's Forensic Pathology eds. Pekka Saukko \& Bernard Knight Arnold, London 3rd Ed 2004: 361-363

8. Purdue BN. Asphyxial and related deaths. Chapter 15. In: The Pathology of Trauma. Ed Mason JK, Purdue BN. 2000 Arnold Publishing, London UK.
9. Hunsaker DM, Hunsaker 3rd JC. Therapyrelated cafe' coronary deaths. Two case reports of rare asphyxial deaths in patients under supervised care. Am J Forensic Med Pathol 2002;23:149-54.

10. Bockholdt B, Ehrlich E, Maxeiner $\mathrm{H}$. Forensic importance of aspiration. Legal Med 2003;5:S311-4.

11. Byard RW. Mechanisms of unexpected death in infants and young children following foreign body ingestion. $\mathrm{J}$ Forensic Sci1996;41:438-41.

12. Stack MM: Clinical forensic Medicine, physician's guide Examination of drunken driver. 2004;

13. Rubart, Michael; Zipes, Douglas P. (2005). "Mechanisms of sudden cardiac death". Journal of Clinical Investigation 115 (9): 2305-2315. doi: 10.1172/JCI26381. ISSN 0021-9738. PMC 1193893. PMID 16138184.

14. Wick R1, Gilbert JD, Byard RW.Café coronary syndrome-fatal choking on food: an autopsy approach. J Clin Forensic Med. 2006 Apr;13 (3):135-8.

15. Jacob B, Wiedbrauck C, Lamprecht J, Bonte W. Laryngologic aspectsof bolus asphyxation - bolus death. Dysphagia 1992;7:31-5.

16. Edirisinghe PAS, A Cafe coronary death due to a banana. Sri Lanka Journal of Forensic Medicine, Science and Law. 2010; 1(1): pp. $22-24$

17. Charaschaisri W. Café coronar syndromefatal choking on 'BANANA'. Indian Journal of Forensic Medicine and Toxicology 5(2):18-19. July 2011. 